\title{
Characterization of Social Capital Using a Nested Latent Class Model: Case of Rural Areas in Central Malawi
}

\author{
Joseph Dzanja $^{1}$ \\ ${ }^{1}$ Department of Agribusiness Management, Lilongwe University of Agriculture and Natural Resources, Malawi \\ Correspondence: Joseph Dzanja, Department of Agribusiness Management, Lilongwe University of Agriculture \\ and Natural Resources, Malawi. E-mail: jdzanja@bunda.luanar.mw
}

Received: October 4, 2017

Accepted: February 13, $2018 \quad$ Online Published: March 15, 2018

doi:10.5539/jas.v10n4p178

URL: https://doi.org/10.5539/jas.v10n4p178

\begin{abstract}
Social capital relates to capital created when a group of individuals or organizations develop the ability to work together for mutually productive gain. Gains in economic performance and innovative capacity depend on the institutional effectiveness of these relationships as measured by the available stock of social capital. Studies on social capital have however, been criticized for failing to account for the multi-dimensional and latent nature of the concept. Using household survey data from Malawi, this study uses latent class analytical methods to explore social capital and how it relates to welfare of people in rural communities in Malawi in Africa. It highlights the usefulness of latent class analytical methods for providing statistically valid information about the characteristics and determinants of social capital. Using the social capital dimensions of trust, participation and volunteering a four class LCA typology was constructed. Around $30 \%$ of the sample were classified as 'trusty participants', reporting active participation in the socio-economic activities of their communities and a high degree of community and institutional trust. Multinomial logistic regression revealed the covariates of the different typologies of social capital.
\end{abstract}

Keywords: social capital, latent class analysis, multi-dimensionality, rural Malawi

\section{Introduction}

An important development in social science over the last decade is the increasing recognition of the role of social capital for explaining socio-economic phenomena (Durlauf \& Fafchamps, 2004). Social capital refers to 'connections among individuals-social networks and the norms of reciprocity and trustworthiness that arise from them' (Putnam, 2000, p. 19). These three concepts 'enable participants to act together more effectively to pursue shared objectives' (Putnam, 2000, p. 56). The concept of social capital has been applied to a wide range of fields of study including economics, development, sociology, health, education and psychology (Dzanja, 2010). Although social capital is now widely recognized and used, there is still debate regarding its theoretical definition and empirical measurement (Lin, 2001; Fukuyama, 1997; Rose et al., 1997; Bourdieu, 1986; Coleman, 1990; Stone, 2001). In particular, Stone (2001) argues that many of the current attempts to empirically measure social capital fail to recognise and account for its multi-dimensional nature. Further, it is argued that social capital is a 'latent' variable. That is, it cannot be directly observed or measured, but must instead be inferred from other observable variables or indicators (Bollen, 2002).

Statistical approaches used to measure social capital have generally failed to account for the multi-dimensional and latent characteristic of social capital. A solution proposed by Owen and Videras (2009) is to use latent class analysis (LCA), which is a statistical method for specifying latent variables from multivariate categorical data (Lazarsfeld, 1950). In their application, Owen and Videras (2009) demonstrate LCA's potential to define different groups of social capital that are qualitatively different and are consistent with an interpretation that social capital is an unobservable multi-dimensional construct. However, their research used secondary data from the US General Social Survey, which was not specifically collected for understanding social capital and its relationship to other variables. Specific data that adequately reflects aspects of social capital will therefore be needed for latent class analysis to provide convincing results (Stone, 2001).

Using a case study from Malawi, this paper demonstrates how latent class analysis can be used to define and measure social capital using data specifically collected for the purpose. To do this, we develop a novel 'nested latent class model' of social capital. This is achieved by first applying LCA to define and measure four different 
dimensions of social capital and then by using the LCA dimension models to define and measure the social capital of the survey sample. The study is novel in the way that it includes a more comprehensive analysis of social capital and is based on empirical data. Given the relatively few studies that have assessed social capital in developing countries (Durlauf \& Fafchamps, 2004), this paper will also make an important contribution to knowledge on the measurement of social capital and its influence on rural development outcomes in a developing country context.

This paper first discusses the different dimensions of social capital then introduces latent class modelling highlighting the way it can improve on previous studies. The methods used in the research, including the case study, are explained, followed by presentation of the results and discussion.

\section{Capturing the Multi-Dimensionality of Social Capital}

The theory of social capital has been criticized for its definitional diversity (Stone, 2001); which has led to serious conceptual ambiguities and vagueness (Durlauf \& Fafchamps, 2004). This lack of commonality is, in part, due to the fact that the definition and measurement of social capital has been based on a range of different dimensions. Table 1 highlights four dimensions most commonly used to measure social capital: Community trust, Institutional trust, Groups and networks, and Volunteerism and participatory activities. However, we note that the majority social capital studies have focused on only a single dimension (Table 1). We argue that this restricted assessment of the dimensions of social capital is perhaps a key contributing factor to the definitional ambiguities currently found in the literature. This proposition is supported by Hean et al. (2003), who argue that a focus on a single dimension will be unable to fully explain the concept.

Table 1. Examples of social capital dimensions

\begin{tabular}{|c|c|c|c|}
\hline Dimension & Description of dimension & Authors & Specific example for use of dimension \\
\hline \multirow{3}{*}{ Trust } & $\begin{array}{l}\text { Trust among community members } \\
\text { or elements of interpersonal } \\
\text { behaviour which fosters greater } \\
\text { cohesion and more robust collective } \\
\text { action in communities }\end{array}$ & $\begin{array}{l}\text { Narayan \& Pritchett, 1999; } \\
\text { Putnam et al., 1993; } \\
\text { Coleman, 1988; } \\
\text { Kawachi et al., 1999; } \\
\text { Lemmel, 2001; }\end{array}$ & $\begin{array}{l}\text { Veenstra (2000) used community trust to } \\
\text { study relationship between social capital } \\
\text { and health for the elderly }\end{array}$ \\
\hline & & Veenstra, 2000 & \\
\hline & $\begin{array}{l}\text { Trust between individual and/or } \\
\text { communities with institutions (e.g. } \\
\text { public institutions) }\end{array}$ & $\begin{array}{l}\text { Lyon, 2000; } \\
\text { Stone, 2001; } \\
\text { Cox \& Caldwell, 2000; } \\
\text { Uslaner, 1999; } \\
\text { Rothstein \& Stolle, } 2002\end{array}$ & $\begin{array}{l}\text { Rothstein and Stolle (2002) studied the } \\
\text { relationship between people and various } \\
\text { institutions using Swedish Data }\end{array}$ \\
\hline Volunteering Activities & $\begin{array}{l}\text { Ability of people to voluntarily } \\
\text { work together and help one another } \\
\text { toward resolving communal issues }\end{array}$ & $\begin{array}{l}\text { Weitzman, 2000; } \\
\text { Wilkinson \& Bittman, } 2002\end{array}$ & $\begin{array}{l}\text { Weitzman (2000) used volunteering to } \\
\text { study linkage between social capital and } \\
\text { binge drinking in USA }\end{array}$ \\
\hline Participatory activities & $\begin{array}{l}\text { Ability of people to participate in } \\
\text { social and economic activities }\end{array}$ & $\begin{array}{l}\text { Putnam et al., 1993; } \\
\text { Guiso et al., 2004; } \\
\text { Onyx \& Bullen, 2000; } \\
\text { Woolcock \& Narayan, 2000; } \\
\text { Shah et al., } 2001\end{array}$ & \\
\hline
\end{tabular}

Social capital is therefore multi-dimensional. It comprises networks of social relations characterised by norms of trust and reciprocity. Definitions of social capital and tools to measure social capital should account for this range of dimensions. Stone (2001, p. 1) however argues that 'there is a gulf between theoretical understandings of social capital and the ways social capital has been measured in much of the empirical work'. Owen and Videras (2009) extend this argument by stating that 'Although many researchers agree social capital is a multidimensional concept, few have applied multivariate methods'.

Table 2 provides a summary of the various multivariate statistical methods that have been used to measure social capital. Many of these multivariate methods, however, have weaknesses (Owen \& Videras, 2009). Regression based methods have been used to explain various aspects of social capital and some of them have used multiple social capital variables in recognition of its multidimensionality. The latent nature of social capital has however been ignored in these studies. Besides, most of these analytical methods assume the normal distribution of the 
manifest and latent variables which may not always hold. Factor analysis has also been used to reduce multiple social capital variables to a few categories of social capital. One weakness of the factor analysis, however, is that it allows researchers to rotate the factor loadings to obtain a meaningful interpretation of the solution; as such the results are not unique. Traditional clustering approaches have also been used in the analysis of social capital (Percy \& Iwaniec, 2007), though the classification process is ad hoc (Owen \& Videras, 2006).

Table 2. Examples of multivariate analytical methods used in social capital studies

\begin{tabular}{ll}
\hline Analytical Methods & Authors \\
\hline Regression & Martin et al., 2004; Isham, 2002 \\
Factor Analysis/Principal Components Analysis & Sabatini, 2005; Hjøllund et al., 2000; Paxton, 1999 \\
Structural Equations & Glaeser et al., 2002; Fafchamps \& Minten, 2001 \\
Cluster Analysis & Percy \& Iwaniec, 2007 \\
Network Analysis & Borgatti \& Everett, 1997 \\
Latent Class Analysis & Owen \& Videras, 2009 \\
\hline
\end{tabular}

In the last decade interest has shifted towards model-based approaches for latent variables. Model based approaches use estimated membership probabilities to classify cases into appropriate clusters (Vermunt \& Magidson, 2002). Latent class analysis (LCA) is one of such method. LCA is a statistical method for finding discrete subtypes of related cases (latent classes) from multivariate categorical data. The method was introduced by Lazarsfeld (1950). Goodman (1974) made the model applicable in practice by developing an algorithm for obtaining maximum likelihood estimates of the model parameters. The Owen and Videras (2009) study is, to our knowledge, the only application of LCA to the analysis of social capital.

LCA would appear to have a number of advantages over other statistical techniques for the measurement of social capital. First, unlike traditional cluster analysis, LCA is model-based and there exist formal criteria to decide on the dimensionality of the latent variable; that is, there are formal criteria to decide on the number of types of social capital that are present in the data (Owen \& Videras, 2009). Second, unlike most traditional regression analysis where the research subjects are treated as homogeneous (an assumption that is not necessarily true), LCA creates a set of typologies of individuals with similar characteristics and this allows for a more in-depth analysis of each typology, thus exposing inherent differences and similarities among such typologies. LCA should therefore provide a much better analysis of the type and structure of social capital, including taking account of its multidimensional and the latent nature of the indicators used to measure it (Paldam, 2000).

\section{Case Study: Social Capital and Welfare in Central Malawi}

The context for this research was to explore the contribution that social capital brings to promoting welfare in rural Malawi. The research involved characterizing social capital and its relationship to welfare variables using LCA methods. Malawi is one of the world's poorest countries with a per capita income of just US\$170 per annum. Its economy is overwhelmingly agrarian with agriculture accounting for nearly $90 \%$ of foreign exchange earnings and 85\% of employment; though only one-third of GDP (Magalasi, 2005). Poverty in Malawi is both chronic and widespread, and afflicts about $65 \%$ of the population. Several indicators highlight poverty including acute and widespread household food insecurity (40-50\%), low literacy rate (58\%), low quality of education and low life expectancy (from 43 years in 1996 to 39 years in 2000).

Understanding social capital with its emphasis on social relationships is important in Malawi because many people have little access to money (the most common indicator of welfare) and strong social relationships are crucial for maintaining livelihoods. Portes (1998) observes that whereas economic capital is in people's bank accounts and human capital is inside their heads; social capital inheres in the structure of the relationships between people. Social capital in rural central Malawi takes many varied forms. Neighbours have a tendency to do some economic activities together. For example, to facilitate farming activities neighbours or relatives may take turns to work as a group on each others' fields. Often a meal is cooked or beer brewed to reward the workers. The work could also be non-agricultural, such as constructing a house or digging a well. Sometimes groups of young people might form themselves into a work gang and hire themselves out (Whiteside \& Malawi, 1999). Malawians also have a tendency to support one another financially or in kind, especially among family members. Children working in the cities tend to send money and other resources to their parents and some relatives in the villages, thus reducing rural economic hardships (Davies et al., 2006). Rural people also have various forms of safety nets from Government and other institutions in the form of food stumps when food is very scarce. These 
vertical relationships are very common as Government implements targeted agricultural input programmes in which poor families are helped with subsidized fertilizers and maize seed to boost food production.

Social capital is about informal networks-involving cooperation within the household or among face-to-face groups within a village. Such kind of cooperation is common in Malawi (Vajja \& White, 2006). Understanding the nature of social capital in important because it allows policy makers to determine how it can be harnessed in development activities in poor countries. The application of LCA in the analysis of social capital exposes its different typologies and characteristics and to our knowledge this is the first time such an analysis has been undertaken in a developing country context.

\section{Method}

\subsection{Data Collection}

Data for this study was collected through a household survey of 478 small holder farmers in two districts of the central region of Malawi: 255 households in Dowa and 223 households in Lilongwe. The two districts are similar in terms of economic/subsistence activities undertaken by the majority of households (i.e. crop production). However, poverty is far higher in Lilongwe district (76.7\%) than in Dowa (49.8\%). It was hypothesised that the differences in welfare between the two districts would (at least in part) be explained by the levels of social capital in those districts.

The data was collected using semi-structured questionnaires. The focus of the questionnaires was to gather information relating to the four key dimensions of social capital (Table 1). The first column in Table 3 provides an outline of the issues that were used to represent these four social capital dimensions. The questionnaire also collected data on socio-demographics, economic livelihoods, household assets endowment and food security. These data are used to characterise the individuals classified into the different social capital groups.

\subsection{Model Formulation and Data Analysis}

Latent class analysis normally starts by defining a categorical latent variable based on a set of discrete observed manifest variables. Initially, we attempted to develop a latent class model for social capital based on sixteen manifest variables that covered the range of dimensions of social capital (Table 3 ). However, it was found that such a model was too complex.

As an alternative, a 'nested' latent class model was devised. In this nested model, we ran separate LCA models for the four key dimensions of social capital (i.e. community trust, institutional trust, volunteerism and participatory activities), and then used these four dimensional LCA models as the manifest variables for a LCA on social capital. Thus the dimensional LCA models are nested within the social capital LCA model. Data for this analysis came from the semi-structured interviews, where each of the four dimensional LCA models was based on the responses to four survey questions. For example, the manifest variables for the 'community trust' dimension LCA model were based on the responses to questions on: Trust among neighbours in the community; Trust with respect to money; Perception that trust in the community has improved or otherwise; and Trust with respect to livestock. The questions used as the manifest variables for all the four dimensions LCA models can be found in Table 3.

The specification of the LCA is defined below and is based on the notation from Goodman (1974). First, let us assume that there is a cross-classification table of $\mathrm{M}=4$ variables, $A, B, C$ and $D$. Also, assume that variable $A$ can take values $i=1, \ldots, I$, variable $B$ can take values $j=1, \ldots, J$, and so on. In this application, the variables represent either the dimensions of social capital (i.e. community trust, institutional trust, volunteering activities, or participatory activities), or social capital as defined in the nested model. Assume that there is one latent variable $\mathrm{X}$ that can take values $t=1, \ldots, T$. The different levels of the latent variables $X$ are referred to as latent classes. Let $\pi_{i j k l t}^{A B C D X}$ denote the joint probability that an individual will be at level $(i, j, k, l, t)$ with respect to the joint variables $(A, B, C, D, X)$. We assume that,

$$
\pi_{i j k l t}=\sum_{t=1}^{T} \pi_{i j k l t}^{A B C D X}
$$

That is, every individual belongs to one and only one of the latent classes, i.e. the latent classes are exhausting and mutually exclusive. In addition, we assume local independence:

$$
\pi_{i j k l t}^{A B C D X}=\pi_{t}^{X} \pi_{i t}^{\bar{A} X} \pi_{j t}^{\bar{B} X} \pi_{k t}^{\bar{C} X} \pi_{l t}^{\bar{D} X}
$$

Where, $\pi_{t}^{X}$ is the probability that an individual will be at level $t$ with respect to the latent variable $X$. $\pi_{i t}^{\bar{A} X}$ is the conditional probability that an individual will be at level $i$ with respect to variable $A$, conditional on being at level $\mathrm{t}$ with respect to the latent variable $X$. The three other conditional probabilities $\pi_{j t}^{\bar{B} X}, \pi_{k t}^{\bar{C} X}$ and $\pi_{l t}^{\bar{D} X}$ are 
defined analogously. The latent class probabilities $\pi_{t}^{X}$ constitute along with the conditional probabilities $\pi_{i t}^{\bar{A} X}$, $\pi_{j t}^{\bar{B} X}, \pi_{k t}^{\bar{C} X}$ and $\pi_{l t}^{\bar{D} X}$ the fundamental quantities of latent class analysis.

The analysis typically begins by fitting a single-class $(T=1)$ baseline model $(\mathrm{H} 0)$, which specifies mutual independence among the variables. Model H0:

$$
\pi_{i j k l}=\pi_{i}^{A} \pi_{j}^{B} \pi_{k}^{C} \pi_{l}^{D}
$$

Assuming that this null model does not provide an adequate fit to the data, a two-class LCA $(T=2)$ model is then fitted to the data. This process continues by fitting successive LCA models to the data, each time adding another class, until the simplest model is found that provides an adequate fit.

Goodness of fit tests for latent class models are conducted using likelihood ratio chi-square statistic $\mathrm{L}^{2}$ (Vermunt \& Magidson, 2002). Model selection was done using the Bayesian Information Criteria (BIC) statistic (Schwarz, 1978) and the Akaike Information Criteria (AIC) (Akaike, 1981). We report the BIC statistic only in this paper. A model with a lower BIC value is preferred over a model with a higher BIC value. Efficiency of class allocation is assessed through the computation of the Pi-star index (Rudas et al., 1994; Boyd et al., 2008). A thorough explanation of latent class analysis is explained in Hagenaars and McCutcheon (2002).

In this research, we were also interested in identifying the determinants of social capital, i.e. what socio-economic characteristics of respondents resulted into membership of the different social capital latent classes. The determinants of social capital were identified through a multinomial logit model in which the latent classes from the nested social capital LCA model were converted into nominal dependent variables and regressed on a number of socio-economic variables. The socio-economic variables used in this analysis included gender, mean per capita expenditure, value of household assets, land endowment, food security status, literacy, marital status and age of household heads. One sample T-tests were then used to determine if the sample mean in each social capital latent class was statistically different from the mean of the whole sample.

\section{Results}

\subsection{Latent Class Analysis}

The results of the LCA analysis are presented in two sections. First, Section 5.2 presents the results of the four LCA models that represent the four dimensions of social capital. Section 5.3 then presents the result for the nested LCA on social capital.

\subsection{Analysis of LCA Models of the Four Dimensions of Social Capital}

The first stage of our analysis involves the specification of four separate LCA models on the four key dimensions of social capital. In this section, we report the findings from each of these four dimensional LCA models. This is then followed by an analysis of the socio-economic determinants of each of the latent classes from the four dimensional LCA models.

\subsubsection{Community Trust}

The first dimension of social capital investigated was community trust. A baseline LCA model (specified using a single $T=1$ class: see Equation (3) was initially estimated. A likelihood ratio chi-square test rejected the null hypothesis that this single class model provides an adequate fit to the data $\left(\chi^{2}=83.6963 ; p<0.001\right)$. This result confirms the existence of multiple classes. The next step is then to run a series of different LCA models in which the number of classes are increased (we tested models that comprised up to four classes). The favoured model in terms of number of classes can be identified using the BIC statistics. These statistics indicated that a three-class model was favoured for the community trust dimension: $\mathrm{BIC}=-28.27$ (compared to 8.17 for the single-class model). The goodness of fit for the three-class model was also good (Pi-star $=0.01)$.

Conditional probabilities for the selected models are shown in Table 3. For the community trust model, Classes 1 and 2 respectively accounted for $46 \%$ and $43 \%$ of the sample respondents; Class 3 had $11 \%$ of the respondents.

Members of Class 1 had high probabilities with respect to the indicators of community trust: $86 \%$ of individuals included in this class stated that they trusted their neighbours in the community, $60 \%$ trusted others with their money, 55\% perceived that trust in the community had improved, and $97 \%$ stated that they trusted other with their livestock. Individuals allocated to Class 1 were labelled as having 'High Community Trust' because of their perception that people can be trusted. Members of Class 2 trusted other in the community with respect to money $(88 \%)$ and livestock assets $(68 \%)$. However, only $36 \%$ of these individuals perceived that community trust had improved. Such individuals therefore appear to be more sceptical about the level of trust in the future. Based on this, members of Class 2 were considered as having 'Moderate Community Trust'. Class 3 has lower probabilities in all of the community trust variables. These are individuals whose perception was that level of 
trust among community members was very low and that their neighbours can not be trusted. The individuals were labelled 'Low Community Trust'.

\subsubsection{Institutional Trust}

Model selection statistics for Institutional Trust dimension indicates that the three-class model is the preferred model. The BIC statistic for the three-class model was 25.84 (compared to 703.12 in the one-class model). Class 1 and 2 respectively account for $26 \%$ and $20 \%$ of respondents, while Class 3 accounts for just over $54 \%$ of the respondents (Table 3). Individuals in Class 1 have high probabilities in all indicators of institutional trust and are labelled 'High Institutional Trust'. Individuals in Class 2 have mixed characteristics. They tend to have high probabilities in their contacts with the government on community problems and parliamentarians on personal problems. Such individuals were coined 'Moderate Institutional Trust'. The final class, Class 3, constitutes individuals who had low institutional trust as they had low probabilities of contacts with either government officials or parliamentarians. They are coined 'Low Institutional Trust'.

\subsubsection{Volunteerism}

Four different models were run for voluntary activities after the hypothesis of a single class model was rejected iThe BIC statistics indicated that a two-class model was preferred (BIC $=-26.01$ compared to $\mathrm{BIC}=85.70$ for the base model). The computed pi-star was 0.07 .

The first class comprised $73 \%$ of the respondents (Table 3). These individuals were labelled 'active volunteers' as they had high probabilities of undertaking a range of volunteering activities including: transporting the sick to the hospital; visiting and helping the elderly; voluntary road maintenance and clearing the cemetery. These are individuals who are able to commit their time and other resources to help the vulnerable members of the communities and be part of the collective action to improve the welfare of the communities. Class two respondents were 'reluctant volunteers'. Although they would transport the sick to hospital and to some extent help the elderly, they were less likely to volunteer to help with other community activities.

\subsubsection{Participatory Activities}

The final dimension of social capital investigated was participatory activities in the context of the community. A two class model of participatory activities was favoured: $\mathrm{BIC}=-13.16$; pi-star $=0.10$. The first class 'Active participants' comprised $65 \%$ of survey respondents (Table 3). Members of this class tended to higher probabilities of participation in a wide range of community activities. Individuals in Class 2 had low probabilities in all the manifest variables and are therefore considered as 'reluctant participants'. 
Table 3. Conditional probabilities for different LCA models across the four dimensions of social capital

\begin{tabular}{|c|c|c|c|}
\hline & Class 1 & Class 2 & Class 3 \\
\hline Community trust & High community trust & Moderate community trust & Low community trust \\
\hline Proportion of respondents allocated to class & 0.46 & 0.43 & 0.11 \\
\hline Trust among neighbours in the community & 0.86 & 0.74 & 0.03 \\
\hline Trust with respect to money & 0.60 & 0.88 & 0.21 \\
\hline Perception that community trust has improved & 0.55 & 0.36 & 0.23 \\
\hline Trust with respect to livestock & 0.97 & 0.68 & 0.01 \\
\hline Institutional trust & High institutional trust & Moderate institutional trust & Low institutional trust \\
\hline Proportion of respondents allocated to class & 0.26 & 0.20 & 0.54 \\
\hline Contact with government on personal problems & 0.99 & 0.25 & 0.01 \\
\hline Contact with government on community problems & 0.84 & 0.88 & 0.07 \\
\hline Contact with parliamentarians on personal problems & 0.93 & 0.75 & 0.10 \\
\hline Contact with parliamentarians on community problems & 0.93 & 0.18 & 0.01 \\
\hline Volunteering & Active Volunteers & Reluctant Volunteers & \\
\hline Proportion of respondents allocated to class & 0.73 & 0.27 & \\
\hline Taking the sick to hospital & 0.88 & 0.57 & \\
\hline Visiting and helping the elderly & 0.94 & 0.39 & \\
\hline Voluntary road maintenance & 0.84 & 0.26 & \\
\hline Clearing the Cemetery & 0.83 & 0.29 & \\
\hline Participatory Activities & Active participants & Reluctant participants & \\
\hline Proportion of respondents allocated to class & 0.65 & 0.35 & \\
\hline Participation in community's social events & 0.85 & 0.61 & \\
\hline Participation in local development projects & 0.92 & 0.39 & \\
\hline Membership in local community organizations & 0.82 & 0.46 & \\
\hline Participation in community action in emergency & 0.85 & 0.23 & \\
\hline
\end{tabular}

\subsection{Analysis of the Nested Latent Class Model on Social Capital}

The final stage in developing a nested latent class model of social capital was to use the latent class typologies from each of the four social capital dimensions as manifest variables of the nested LCA model for social capital. A likelihood ratio chi-square test rejected the null hypothesis that a single class model provided an adequate fit to the data $\left(\chi^{2}=43.04 ; p<0.001\right)$. This result confirms the existence of multiple classes describing social capital. The favoured multiple class model was a four-class model: $\mathrm{BIC}=-0.53$ (compared to 100.67 for the single-class model). The goodness of fit of the four-class model was also acceptable $(\mathrm{Pi}-\mathrm{star}=0.10)$.

Table 4 reports the conditional probabilities for the nested LCA model on social capital.

$>$ Class 1 ( $27 \%$ of the sample) had high probabilities for institutional trust, but low levels of community trust and were reluctant participants in community activities. These individuals were labelled 'Institutionally connected'.

$>$ Class 2 (18\% of the sample) had high probabilities volunteering and high levels of institutional trust. However, they tended not to participate in community activities. These individuals were labelled 'Institutional volunteers'.

> Class 3 (accounting for $30 \%$ of the survey sample) has high probabilities for participatory activities and both community and institutional trust. Individuals included in this class were therefore labelled as 'Trusty participants'.

$>$ The final class accounted for $25 \%$ of survey respondents. Class 4 has high probabilities in both volunteering and participatory activities, but had the low level of trust in either the community or institutions. Individuals in this class were labelled 'volunteering participants'. 
Table 4. Conditional probabilities for the Nested LCA model for social capital

\begin{tabular}{|c|c|c|c|c|c|}
\hline \multirow[b]{2}{*}{ Social capital Dimensions } & \multirow[b]{2}{*}{ Qualitative Characteristics } & \multirow{2}{*}{$\begin{array}{l}\text { Class } 1 \\
\text { Institutionally } \\
\text { connected }\end{array}$} & \multirow{2}{*}{$\begin{array}{l}\text { Class } 2 \\
\text { Institutional } \\
\text { volunteers }\end{array}$} & \multirow{2}{*}{$\begin{array}{l}\text { Class } 3 \\
\text { Trusty } \\
\text { participants }\end{array}$} & \multirow{2}{*}{$\begin{array}{l}\text { Class } 4 \\
\text { Volunteering } \\
\text { participants }\end{array}$} \\
\hline & & & & & \\
\hline & Proportion of respondents allocated to class & 0.27 & 0.18 & 0.30 & 0.25 \\
\hline \multirow[t]{3}{*}{ Community trust } & High community trust & 0.04 & 0.48 & 0.58 & 0.29 \\
\hline & Moderate community trust & 0.40 & 0.16 & 0.28 & 0.20 \\
\hline & Low community trust & 0.56 & 0.36 & 0.14 & 0.51 \\
\hline \multirow[t]{3}{*}{ Institutional trust } & High institutional trust & 0.59 & 1.0 & 0.57 & 0.40 \\
\hline & Moderate institutional trust & 0.25 & 0.0 & 0.30 & 0.40 \\
\hline & Low institutional trust & 0.16 & 0.0 & 0.13 & 0.20 \\
\hline \multirow[t]{2}{*}{ Volunteering } & Active volunteers & 0.45 & 1.0 & 0.31 & 0.89 \\
\hline & Reluctant volunteers & 0.55 & 0.0 & 0.69 & 0.11 \\
\hline \multirow[t]{2}{*}{ Participatory activities } & Active participants & 0.0 & 0.10 & 1.0 & 0.67 \\
\hline & Reluctant participants & 1.0 & 0.90 & 0.0 & 0.32 \\
\hline
\end{tabular}

The conditional probabilities in Table 4 table reflect the prevalence of a particular social capital aspect. As such, the figures represent the levels of social capital in a particular latent class with respect to the social dimensions under study. If we take probabilities of $>0.5$ as relatively high in social capital with respect to a particular dimension and vice versa, then trusty participants (Class 3) could be considered as the group with the highest social capital. The institutionally connected (class 1) only registered high social capital with respect to institutional trust, as such, they could be considered as a group with low social capital. Latent class modelling therefore not only creates distinct groups of individuals with different socio-economic characteristics, it also helps to quantify the levels of social capital.

\subsection{The Nested LCA Model and Measures of Welfare}

The next step in the analysis was to test whether the four latent classes provided a functional typology capable of distinguishing rural people on a range of other social economic measures. This was achieved using a comparative analysis on a range of indicators of welfare including income (represented by per capita expenditure), household assets, endowment of arable land, food security (represented by yield in $\mathrm{Kg}$ per ha of maize), and on education attainment (Table 5). A one sample t-test was used to test the differences between the mean values of the variables for each class with that of the whole sample (Table 5).

The results demonstrated that, in general, the institutionally connected were better off in terms of land endowment, but were worse off with respect to income, as measured through per capita expenditure; while the institutional volunteers were better off with respect to income and were worse off with respect to land and food security. The trusty participants were better off with respect to household physical assets and food security and were worse off with respect to income. The volunteering participants were better off with respect to both income and food security, though they were worse off with respect to farm land endowment. There were no significant differences among the classes with respect to educational attainment.

Table 5. Quantitative characteristics of latent class memberships (one sample t-test analysis)

\begin{tabular}{llllll}
\hline & $\begin{array}{l}\text { Per capita } \\
\text { expenditure }(\mathrm{MK})\end{array}$ & $\begin{array}{l}\text { Land endowment } \\
\text { (ha) }\end{array}$ & $\begin{array}{l}\text { Physical assets } \\
(\mathrm{MK})\end{array}$ & $\begin{array}{l}\text { Food Security } \\
\text { (Maize yield) }(\mathrm{kg} / \mathrm{ha})\end{array}$ & $\begin{array}{l}\text { Education } \\
\text { (years) }\end{array}$ \\
\hline Institutionally connected & $3.79^{* * *}$ & $\mathbf{2 . 9 8}^{* * *}$ & 142,730 & 1,490 & 4.26 \\
Institutional volunteers & $\mathbf{5 . 7 2}^{* * * *}$ & $1.64^{*}$ & 122,900 & $1,423^{* *}$ & 4.20 \\
Trusty participants & $3.69^{* * *}$ & 1.81 & $\mathbf{1 7 4 , 2 4 0}^{* * *}$ & $\mathbf{1 , 8 6 0 ^ { * * * }}$ & 4.32 \\
volunteering participants & $\mathbf{5 . 5 0}$ & $1.67^{* *}$ & 137,190 & $\mathbf{1 , 9 9 0}^{* * *}$ & 4.09 \\
Overall Mean & $\mathbf{4 . 6 3}$ & $\mathbf{2 . 1 0}$ & $\mathbf{1 4 4 , 0 0 0 . 0 0}$ & $\mathbf{1 , 5 9 9 . 0 0}$ & $\mathbf{4 . 2 2}$ \\
\hline
\end{tabular}

Note. ${ }^{* * *}(\mathrm{P}$-value $<0.000) ; * *(\mathrm{P}$-value $<0.05) ; *(\mathrm{P}$-value $<0.10)$.

Bold indicates that the social capital class was better off in terms of the socio-economic attribute, while italic means the opposite.

Exchange rate: 1 US $\$=$ MK140.00. 


\section{Determinants of Rural Social Capital}

Table 6 presents the results of the multinomial logistic regression analysis. (The institutionally connected were a reference category). The multinomial logistic regression assumes that there is no order to the categories of the outcome variable, i.e. the variable is nominal. In this case the outcome variable was the allocation of research subjects into the four classes. One important feature of the multinomial logistic model is that it estimates $k-1$ models, where $k$ is the number of levels of the dependent variable (Bland \& Altman, 2000). In this instance latent class 1 (the institutionally-connected) of the dependent variable was set as the referent group. The models for class 2, 3 and 4 membership were estimated relative to latent class 1 . Since the parameter estimates were relative to the referent group, the standard interpretation of the multinomial odds ratio is that for a unit change in the predictor variable, the odds of outcome $m$ relative to the referent group is expected to change by its respective parameter estimate given the variables in the model are held constant.

The statistical analysis was aimed at identifying the socio-economic factors that determined the allocation of the rural people into the different latent social capital classes. The estimates in Table 6 are in the form of odds ratios, which reflect the predicted change in odds of being in any of the classes (outcome $m$ ) for a unit increase in each of the explanatory variables. When the Odds Ratio is less than 1 , increasing values of the explanatory variable corresponds to decreasing odds of being in the class under consideration and vise versa.

The results indicate that household size, having a spouse and geographical location (district of origin) had influence on the allocation on the rural people in all classes except the reference group. Age of household head was associated with being in classes 1 and 2. Gender of a household head and per capita expenditure did not have any significant influence on their being in any of the classes. Human capital in the form of literacy was associated with being institutional volunteers (the reference group) and being among the volunteering participants. This finding confirms the linkage between volunteering and human capital that people that are more educated and thus more skilled are better able to engage in volunteering work in their communities (Wilson, 2000).

The results also show that food security was associated with being in the group of volunteering participants and the reference group (institutional volunteers) and this result confirms the above average productivity for food production for these groups (Table 5).

Table 6. MLR Estimates for social capital typologies

\begin{tabular}{|c|c|c|c|}
\hline \multirow[b]{2}{*}{ Covariates } & Institutionally Volunteers & Trusty Participants & Volunteering participants \\
\hline & $\begin{array}{l}\text { Odds ratios/ } \\
\text { Std errors }\end{array}$ & $\begin{array}{l}\text { Odds ratios/ } \\
\text { Std errors }\end{array}$ & $\begin{array}{l}\text { Odds ratios/ } \\
\text { Std errors }\end{array}$ \\
\hline \multicolumn{4}{|l|}{ Human Capital } \\
\hline Sex & $.98(.17)$ & $0.93(.18)$ & $1.14(.21)$ \\
\hline Literacy & $1.41(.21)^{* *}$ & $1.39(.23)^{* *}$ & $1.16(.09)^{* * *}$ \\
\hline \multicolumn{4}{|l|}{ Household Characteristics } \\
\hline Household size & $1.01(.02)$ & $0.89(.02)^{* * *}$ & $.73(.12)^{* *}$ \\
\hline Age of household head & $1.01(.004)$ & $0.99(.004)^{* *}$ & $0.99(.004)^{*}$ \\
\hline Marital status & $0.78(.12)$ & $.61(.09)^{* * *}$ & $1.22(.19)$ \\
\hline \multicolumn{4}{|l|}{ Income } \\
\hline Per capita expenditure (MK) & $0.99(.04)$ & $1.04(0.4)$ & $1.01(.04)$ \\
\hline \multicolumn{4}{|l|}{ Geographical Location } \\
\hline Location $($ Dowa $=0$ and Lilongwe $=1)$ & $1.26(.18)^{*}$ & $0.67(.11)^{* *}$ & $0.95(.14)$ \\
\hline Distance to paved roads & $1.17(.05)$ & $1.11(.05)^{* *}$ & $.99(.04)$ \\
\hline \multicolumn{4}{|l|}{ Physical Capital } \\
\hline Value of physical assets & $1.12(.02)^{* * *}$ & $1.05(.03)^{* *}$ & $0.93(.02)$ \\
\hline Arable land (ha) & $0.91(.06)$ & $0.91(.07)$ & $0.82(.06)^{* *}$ \\
\hline \multicolumn{4}{|l|}{ Food Security } \\
\hline Food Security dummy variable $($ yes $=1$ and no $=0$ ) & $0.78(.09)$ & $1.75(.09)^{* *}$ & $0.98(.12)$ \\
\hline \multicolumn{4}{|c|}{ Others } \\
\hline Having an IGA (yes $=1$ and no $=0)$ & $1.91(.23)^{* * *}$ & $0.97(.13)$ & $1.95(.23)^{* * *}$ \\
\hline
\end{tabular}

Note. Latent class 1 (the institutionally-connected) was the reference group. 


\section{Discussion}

The research paper set out to explore the applicability of latent class modelling in the characterisation of social capital and identification of its determinants in the developing countries, using the case study of rural Malawi. The basic idea of social capital is that one's family, friends, and associates constitute an important asset, one that can be called upon in a crisis, enjoyed for its own sake, and/or leveraged for material gain (Putnam, 1995). Social capital has therefore being linked to poverty alleviation efforts. Development organizations like the World Bank have advocated support for poor peoples' social capital as one way of alleviating poverty (Woolcock \& Narayan, 2000). The problem with social capital research has centred on its measurement. This research came about against the backdrop of criticisms levelled against many social capital studies as falling short of recognizing the multi-dimensional and latent nature of the construct. The application of latent class analysis dealt with these concerns.

\subsection{Use of Latent Class Analysis}

The nested latent class model used in the study represented a novel analytical framework that resulted in the definition of four different social capital classes. The nested LCA model was based on sixteen social capital indicators that typify four different social capital dimensions (community trust, institutional trust, volunteering and participation). The use of formal information criteria such as BIC and AIC validated the typology through the statistically valid selection of the most parsimonious model. In this case, a four class typology of research subjects was achieved and this allowed for further analysis that exposed how membership into social capital classes affected welfare and also social economic differences and similarities among the four classes and the application of the multinomial logit model to identify the determinants of social capital.

It is worth noting that alternative analytical methods such as traditional regressions, factor analysis, cluster analysis and several others (Table 2) that have been used in the measurement of social capital have helped to shed light on the global understanding of social capital. Many of these analytical methods, however, have tended to use univariate measures of social capital, thus falling short of the need to account for its multidimensionality. Individual social capital variables have not been able to adequately represent social capital. Besides, LC models do not rely on the traditional modeling assumptions which are often violated in practice (linear relationship, normal distribution, homogeneity). Hence, they are less subject to biases associated with data not conforming to model assumptions (Vermunt \& Magidson, 2002).

Few researchers have used multivariate methods to account for multidimensionality in the measurement of social capital. Sabatini (2005) uses principal components analysis to a number of social capital indicators to a single variable while Paxton (1999) applies confirmatory factor analysis to several indicators of trust (Owen \& Videras, 2009), however point out that, latent class models have some advantages over principal components analysis (PCA) and factor analysis (FA). Factor analysis and principal component analysis allows researchers to rotate the factor loadings to obtain a meaningful interpretation of the solution, as such the results are not unique. Besides, these analytical methods assume the normal distribution of the manifest and latent variables which may not always hold and the principal components or factors isolated from these analyses may account for very little variation in the data set. Using the Malawi data, for example, a PCA run on the sixteen variables resulted into 4 principal components. The components however accounted for $51 \%$ of the variability in the original sixteen variables, thus incurring $49 \%$ loss of information. It is therefore notable that while PCA and FA help in the examination of latent relationships among variables and as data reduction tools, they recognise the multidimensional nature of social capital. There is, however, a risk that valuable information could be lost in the process. In addition, though it is possible to identify what variables the components or factors represent, categorical social capital variables can not be addressed. The value of LCA is that it addresses categorical social capital variables.

\subsection{Social and Economic Characteristics of Rural People in Central Malawi}

Latent class analysis sorted the research subjects into distinct social economic classes defined by different social capital endowments. The allocation of research respondents into different latent classes allowed for a comparative analysis of the socio-economic differences among the classes. One sample t-tests (Table 5) analysis showed that members in different classes had significant differences with respect to some selected socio-economic variables. For example, individuals in class one (institutionally connected) had significantly lower than average values for per capita expenditure and their values for food security, and physical assets were also mildly lower than then overall average. In contrast this class had significantly higher than average values for land ownership. Institutional connection in this case was measured by the contacts that the research subjects made seeking help from the government and parliamentarians. Usually, in the Malawian rural situation, poor 
people tend to go to the local authorities to seek help such as free food and agricultural inputs. Despite having large land sizes, it would appear that the institutionally connected people were poor. This network is different from the kind of connection in which an individual would visit the commercial banks to negotiate for loans. On the contrary, the connection involves low resource endowed households desperately seeking help from the available institutions. Volunteering participants on the other hand had different characteristics as they registered statistically higher values for per capita expenditure and maize productivity (food security).

The classification of research respondents in this way therefore exposed the differences in their welfare. This is important because in developing countries where a large number of people live in poverty, the challenge has always been to identify the vulnerable poor or ultra poor of the rural communities to more effectively target development programmes. The Malawian Government and the local NGOs have for the past few years handed out free food stamps to the vulnerable members of the rural communities and this is how such clusters of people have survived the harsh realities of life such as drought and famine and even devastating floods.

The quantitative analysis has shown different levels of social capital and the socio-economic characteristics in different latent classes. Such differences could have enormous welfare policy implications in the rural areas of poor countries. The results show that latent class analysis could be used to map out the social capital typologies prevalent in rural communities with statistically valid results. For example, where volunteering tendencies are prevalent development projects that require volunteering activities could be the most relevant. The socio-economic analysis, however, did not identify the determinants of rural social capital. In this way, a multinomial logit model was run to identify the factors that predisposed research subjects to belong to particular classes.

In addition to the identification of sub groups of social capital, the nested latent class analysis also allowed for the identification of the determinants of social capital. The latent classes were converted into a nominal variable which was then regressed on a number of socio-economic factors in a multinomial logit model. This analytical technique helped to identify the factors that predisposed respondents to be allocated into particular classes. For example, it was found that classification of research respondents into class one (the institutionally connected) was influenced by household sizes, age and place of residence. This means for latent class 1 with respect to the reference class (class 3) a one unit increase in household size and age of the respondents was associated with a $13 \%$ and $2 \%$ increase in the odds of being in class 1 respectively. In other words, the more the household size and the more advanced in age, the more likelihood of being poor. Classes 2 individuals were influenced by household size, literacy, age and ownership of income generating activities. Class 4 was influenced by literacy, household size, location and income generating activities. Since the various classes had different socio-economic characteristics, poverty mapping of communities could be facilitated.

\subsection{Policy Implications}

Development initiatives in the developing countries require an in-depth understanding of target communities. The social capital typologies generated through latent class modelling offered opportunities to understand the target population better. Different sectors of the communities have different social networks. Seemingly homogeneous populations were found to constitute distinct classes with different social economic characteristics. Some segments of the rural communities are passive members who are not actively involved in community activities. Some are even sceptical about the trustworthiness of their fellow community members and some public institutions. Volunteering tendencies were also identified and they help in the building of strong and cohesive communities. Volunteering also fosters trust between citizens and help develop norms of solidarity and reciprocity which are essential to stable communities. If development projects require voluntary participation of the communities, then those with volunteering tendencies could be the best target. The typology of communities according to their endowment of social capital allows for prescriptive allocation of development initiatives. In Malawi there are many challenges that would require voluntary activities such as in the fight against HIV and AIDS, environmental management and in natural disasters such as floods. Therefore policies that target the rural areas should be based on the understanding of the social capital context of such areas.

\subsection{The Way Forward}

The typology of the research subjects was aimed at achieving an understanding of the characteristics of social capital in the rural areas of central Malawi with respect to the employed dimensions. The analysis did not specifically identify how social capital influences economic welfare. Such information would be important in quantitatively understanding the determinants of social capital in Malawi in particular and to the poor countries in general. More research would also be needed to shed light on why some segments of the communities do not participate in social and economic development activities that benefit their communities. 


\section{Conclusion}

This study used a nested latent class model to characterise social capital in rural Malawi by using sixteen social capital variables that characterized the dimensions of community volunteering activities, socio-economic participation, trust among community members and institutional trust. Unlike traditional statistical methods where the allocation of individuals to different sub-groups is not based on an underlying statistical model, the nested latent class model was able to group research subjects into statistically distinct sub-groups which were socio-economically different. Besides, the model allowed for more statistical analysis which resulted into the identification of social capital determinants. These findings have fundamental policy implications as far as rural development is concerned. Latent class analysis has proven to be a reliable method that can map up the social capital prevalence in different rural communities. Such knowledge should help policy makers to understand the social-networking tendencies of rural people and thus identify poverty alleviation projects that could fit such situations.

The use of four dimensions of social capital does not tell the whole story about social capital in rural Malawi, as there are numerous dimensions that have been identified in literature. More detailed research is therefore required to understand the specific mechanism through which rural social capital can be enhanced and welfare levels are influenced by different social capital types.

\section{References}

Akaike, H. (1981). Likelihood of a model and information criteria. Journal of Econometrics, 16, 3-14. https://doi.org/10.1016/0304-4076(81)90071-3

Bollen, K. (2002). Latent variables in psychology and the social sciences. Annual Reviews in Psychology, 53, 605-634. https://doi.org/10.1146/annurev.psych.53.100901.135239

Borgatti, S., \& Everett, M. (1997). Network analysis of 2-mode data. Social Networks, 19, 243-269. https://doi.org/10.1016/S0378-8733(96)00301-2

Bourdieu, P. (1986). The Forms of Social Capital. Handbook of Theory and Research for the Sociology of Education (pp. 241-258).

Boyd, C. P., Hayes, L., Wilson, R. L., \& Bearsley-Smith, C. (2008). Harnessing the social capital of rural communities for youth mental health: An asset-based community development framework. Australian Journal of Rural Health, 16, 189-193. https://doi.org/10.1111/j.1440-1584.2008.00996.x

Coleman, J. (1990). Foundations of Social Theory, Harvard University Press.

Coleman, J. S. (1988). Social Capital in the Creation of Human-Capital. American Journal of Sociology, 94, S95-S120. https://doi.org/10.1086/228943

Cox, E., \& Caldwell, P. (2000). Making social policy (pp. 43-73). Social Capital and Public Policy in Australia, Australian Institute of Family Studies, Melbourne.

Davies, S., Easaw, J., \& Ghoshray, A. (2006). Mental Accounting and Remittances: A Study of Malawian Households. Research Paper, University of Bath.

Durlauf, S. N., \& Fafchamps, M. (2004). Social Capital. NBER Working Paper. Cambridge, MA, National Bureau of Economic Research. https://doi.org/10.3386/w10485

Dzanja, J. (2010). Defining and Measuring Social capital: The Case Study of Malawi Rural Development (PhD Thesis, Institute of Biological, Environmental and Rural Sciences, Aberystwyth University, Aberystwyth, UK).

Fafchamps, M., \& Minten, B. (2001). Social Capital and Agricultural Trade. American Journal of Agricultural Economics, 83, 680-685. https://doi.org/10.1111/0002-9092.00190

Fukuyama, F. (1997). Social capital and the modern capitalist economy: Creating a high trust workplace. Stern Business Magazine, 4, 4-16.

Glaeser, E., Laibson, D., \& Sacerdote, B. (2002). An Economic Approach to Social Capital. The Economic Journal, 112, 437-458. https://doi.org/10.1111/1468-0297.00078

Goodman, L. (1974). Exploratory latent structure analysis using both identifiable and unidentifiable models. Biometrika, 61, 215-231. https://doi.org/10.1093/biomet/61.2.215

Guiso, L., Sapienza, P., \& Zingales, L. (2004). Cultural Biases in Economic Exchange. NBER Working Paper. https://doi.org/10.3386/w11005 
Hagenaars, J., \& Mccutcheon, A. (2002). Applied Latent Class Analysis. Cambridge University Press. https://doi.org/10.1017/CBO9780511499531

Hean, S., Cowley, S., Forbes, A., Griffiths, P., \& Maben, J. (2003). The M-C-M' cycle and social capital. Social Science \& Medicine, 56, 1061-1072. https://doi.org/10.1016/S0277-9536(02)00103-X

Hjøllund, L., Svendsen, G., Economics, D. O., \& Business, A. S. O. (2000). Social capital: A standard method of measurement. Department of Economics, Faculty of Business Administration, Aarhus School of Business.

Isham, J. (2002). The Effect of Social Capital on Fertiliser Adoption: Evidence from Rural Tanzania. Journal of African Economies, 11, 39. https://doi.org/10.1093/jae/11.1.39

Kawachi, I., Kennedy, B., \& Wilkinson, R. (1999). Crime: social disorganization and relative deprivation. Social Science \& Medicine, 48, 719-731. https://doi.org/10.1016/S0277-9536(98)00400-6

Lazarsfeld, P. F. (1950). The logical and mathematical foundation of latent structure analysis \& the interpretation and mathematical foundation of latent structure analysis. Measurement and Prediction. Princeton, NJ, Princeton University Press.

Lemmel, L. (2001). The Dynamics of Social Capital: Creating Trust-Based Relationships and Trustworthy Environments. National Civic Review, 90, 97-104. https://doi.org/10.1002/ncr.90109

Lin, N. (2001). Building a network theory of social capital. Social Capital: Theory and Research (pp. 3-29).

Lyon, F. (2000). Trust, Networks and Norms: The Creation of Social Capital in Agricultural Economies in Ghana. World Development, 28, 663-681. https://doi.org/10.1016/S0305-750X(99)00146-1

Magalasi, C. (2005). People's report on the MGD's: A case of Malawi. Malawi Economic Justice Network. Retrieved December 2, 2008, from http://www.commonwealthfoundation.com/uploads/documents/mdg malawi.pdf

Martin, K., Rogers, B., Cook, J., \& Joseph, H. (2004). Social capital is associated with decreased risk of hunger. Social Science \& Medicine, 58, 2645-2654. https://doi.org/10.1016/j.socscimed.2003.09.026

Narayan, D., \& Pritchett, L. (1999). Cents and Sociability: Household Income and Social Capital in Rural Tanzania. Economic Development and Cultural Change, 47, 871-897. https://doi.org/10.1086/452436

Onyx, J., \& Bullen, P. (2000). Measuring Social Capital in Five Communities. The Journal of Applied Behavioral Science, 36, 23. https://doi.org/10.1177/0021886300361002

Owen, A., \& Videras, J. (2006). Reconsidering Social Capital: A Latent Class Approach. SSRN. https://doi.org/10.2139/ssrn.897955

Owen, A., \& Videras, J. (2009). Reconsidering social capital: A latent class approach. Empirical Economics, 37, 555. https://doi.org/10.1007/s00181-008-0246-6

Paldam, M. (2000). Social Capital: One or Many? Definition and Measurement. Journal of Economic Surveys, 14, 629-653. https://doi.org/10.1111/1467-6419.00127

Paxton, P. (1999). Is Social Capital Declining in the United States? A Multiple Indicator Assessment 1. American Journal of Sociology, 105, 88-127. https://doi.org/10.1086/210268

Percy, A., \& Iwaniec, D. (2007). The validity of a latent class typology of adolescent drinking patterns. Ir $J$ Psych Med, 24, 13-18. https://doi.org/10.1017/S0790966700010089

Portes, A. (1998). Social Capital: Its Origins and Applications in Modern Sociology. Annual Reviews in Sociology, 24, 1-24. https://doi.org/10.1146/annurev.soc.24.1.1

Putnam, R. (2000). Bowling Alone: The Collapse and Revival of American Community. Simon \& Schuster. https://doi.org/10.1145/358916.361990

Putnam, R., Leonardi, R., Nanetti, R., \& Ebrary, I. (1993). Making democracy work: Civic traditions in modern Italy. Princeton University Press Princeton, NJ.

Rose, R., Mishler, W., \& Haerpfer, C. (1997). Getting Real: Social Capital in Post-communist Societies. Centre for the Study of Public Policy, University of Strathclyde.

Rothstein, B., \& Stolle, D. (2002). How Political Institutions Create and Destroy Social Capital: An Institutional Theory of Generalized Trust. 98th Meeting of the American Political Science Association in Boston, MA, August. 
Rudas, T., Clogg, C., \& Lindsay, B. (1994). A New Index of fit based on mixture methods for the analysis of contingency tables. Journal of the Royal Statistical Society. Series B. Methodological, 56, 623-639.

Sabatini, F. (2005). Social capital as social networks: A new framework for measurement and an empirical analysis of its determinants and consequences. Journal of Socio-Economics, 38(3), 429-442. https://doi.org/10.1016/j.socec.2008.06.001

Schwarz, G. (1978). Estimating the dimension of a model. Annals of Statistics, 6, 461-464. https://doi.org/ $10.1214 /$ aos/1176344136

Shah, D., Kwak, N., \& Holbert, R. (2001). "Connecting" and "Disconnecting" with Civic Life: Patterns of Internet Use and the Production of Social Capital. Political Communication, 18, 141-162. https://doi.org/10.1080/105846001750322952

Stone, W. (2001). Measuring Social Capital: Towards a theoretically informed measurement framework for researching social capital in family and community life. Research Paper, 24. Australian Institute of Family Studies.

Uslaner, E. (1999). Democracy and Social Capital. Democracy and Trust (pp. 121-150). https://doi.org/10.1017/ CBO9780511659959.005

Vajja, A., \& White, H. (2006). Community Participation in social funds in Malawi and Zambia. Q-Squared Working Paper No. 20. Retrieved November, 10, 2008, from http://www.q-squared.ca/pdf/Q2_WP20_ Vajja\&white.pdf $\% 20$

Veenstra, G. (2000). Social capital, SES and health: an individual-level analysis. Social Science \& Medicine, 50, 619-629. https://doi.org/10.1016/S0277-9536(99)00307-X

Vermunt, J., \& Magidson, J. (2002). Latent class cluster analysis. Applied Latent Class Analysis (pp. 89-106). https://doi.org/10.1017/CBO9780511499531.004

Weitzman, E. (2000). Giving means receiving: the protective effect of social capital on binge drinking on college campuses. Am Public Health Assoc.

Whiteside, M., \& Malawi, O. I. P. I. (1999). Ganyu Labour in Malawi and Its Implications for Livelihood Security Interventions: An Analysis of Recent Literature and Implications for Poverty Alleviation. The Programme.

Wilkinson, J., \& Bittman, M. (2002). Neighbourly Acts-Volunteering, Social Capital and Democracy. Australian Journal on Volunteering, 7, 32-44.

Wilson, J. (2000). Volunteering. Annual Review of Sociology, 26, 215-240. https://doi.org/10.1146/annurev.soc. 26.1.215

Woolcock, M., \& Narayan, D. (2000). Social Capital: Implications for Development Theory, Research, and Policy. The World Bank Research Observer, 15, 225-249. https://doi.org/10.1093/wbro/15.2.225

\section{Copyrights}

Copyright for this article is retained by the author(s), with first publication rights granted to the journal.

This is an open-access article distributed under the terms and conditions of the Creative Commons Attribution license (http://creativecommons.org/licenses/by/4.0/). 